\title{
Características Morfogênicas e Estruturais do Capim-Xaraés Submetido à Adubação Nitrogenada e Desfolhação ${ }^{1}$
}

\author{
Janaina Azevedo Martuscello², Dilermando Miranda da Fonseca ${ }^{3}$, Domicio do Nascimento \\ Júnior $^{3}$, Patrícia Menezes Santos ${ }^{4}$, José Ivo Ribeiro Junior ${ }^{5}$, Daniel de Noronha Figueiredo \\ Vieira da Cunha ${ }^{2}$, Luciano de Melo Moreira ${ }^{2}$
}

\begin{abstract}
RESUMO - O trabalho foi realizado com o objetivo de se avaliarem as características morfogênicas e estruturais de Brachiaria brizantha cv. Xaraés, submetido a quatro doses de nitrogênio (0, 40, 80 e $\left.120 \mathrm{mg} / \mathrm{dm}^{3}\right)$ e três regimes de desfolhação (três, quatro e cinco folhas completamente expandidas), em um esquema fatorial 4 x 3 . O experimento foi conduzido em casa de vegetação, com os tratamentos dispostos em um delineamento inteiramente casualizado, com quatro repetições. Após desbaste, foram mantidas três plantas por vaso com capacidade de $5,8 \mathrm{dm}^{3}$. As plantas receberam adubação fosfatada e potássica, de acordo com análise de fertilidade do solo. A adubação nitrogenada, via solução aquosa, foi parcelada em quatro aplicações. Quando apresentaram número de folhas expandidas indicador de corte, as plantas foram colhidas a $5 \mathrm{~cm}$ do solo, iniciando-se as avaliações das características morfogênicas e estruturais. Os resultados indicaram que o nitrogênio tem efeito sobre as características morfogênicas e estruturais e sobre a produção de MS, com exceção da MS radicular. Observou-se incremento de até 37\% na taxa de alongamento (cm/dia) para a mais elevada dose de $\mathrm{N}\left(120 \mathrm{mg} / \mathrm{dm}^{3}\right)$ em relação ao tratamento sem adubação nitrogenada. A freqüência de corte influenciou a taxa de alongamento foliar, o filocrono, o comprimento final da lâmina, o número de folhas vivas por perfilhos, a taxa de senescência e o teor matéria seca da parte aérea e raiz.
\end{abstract}

Palavras-chave: Brachiaria brizantha cv. Xaraés, forrageira, matéria seca, morfogênese

\section{Morphogenetic and Structural Characteristics of Xaraésgrass Submitted to Nitrogen Fertilization and Defoliation}

\begin{abstract}
The morphogenetic and structural traits of Brachiaria brizantha cv. Xaraés submitted to the treatment combinations of four nitrogen rates $\left(0,40,80\right.$ and $\left.120 \mathrm{mg} / \mathrm{dm}^{3}\right)$ and three defoliation frequencies (two, four and five completely expanded leaves) were evaluated according to a 4 x 3 factorial arrangement. The experiments were conducted in a greenhouse, with the treatments arranged as factorial combination. The experimental design was completely randomized, with four replications. After thinning, three seedlings were left per pot $\left(5,8 \mathrm{dm}^{3}\right)$. The phosphate fertilization was performed according to the soil fertility. The pots were fertilized with phosphorus and potassium, according to soil fertility. Nitrogen fertilization was split in four applications and applied in aqueous solution. When the plants reached the number of expanded leaves (defoliation moment), they were cut at $5 \mathrm{~cm}$ height from soil level before evaluation of morphogenetic and structural traits in the aftermath. Significant nitrogen effect was observed on morphogenetic and structural characteristics of xaraésgrass and on DM yield, except on root DM. Leaf elongation rate (LER) increased linearly up to $37 \%$ at the $\mathrm{N}$ rate of $120 \mathrm{mg} / \mathrm{dm}^{3}$. Defoliation influenced leaf elongation rate, phyllochron, blade length, number of live leaves per tiller, senescence rate and dry matter yield of shoot and root.
\end{abstract}

Key Words: Brachiaria brizantha cv. Xaraés, dry matter, forage, morphogenesis

\section{Introdução}

O lançamento de novos cultivares de gramíneas forrageiras resulta da demanda crescente pela busca por plantas mais competitivas, menos exigentes em fertilidade do solo, com menor sazonalidade de produção e maior resistência a pragas e doenças, entre outros. Em atendimento à essa demanda, o Centro
Nacional de Pesquisa de Gado de Corte (EMBRAPA) lançou o cultivar de Brachiaria brizantha denominado Xaraés. Segundo Valle et al. (2003), o cultivar Xaraés foi liberado com o objetivo de promover a diversificação de espécies forrageiras nas pastagens do gênero Brachiaria, oferecendo opção alternativa de qualidade à $B$. brizantha $\mathrm{cv}$. Marandu, desencorajando, assim, o monocultivo pecuário predominante no Brasil Central.

\footnotetext{
${ }^{1}$ Parte da dissertação do primeiro autor, apresentada ao Programa de Pós-graduação em Zootecnia da UFV

2 Estudante do Programa de Pós-graduação em Zootecnia/UFV (jazevedom@bol.com.br).

3 Professor do Departamento de Zootecnia/UFV (dfonseca@ufv.br; domicio@ufv.br).

${ }^{4}$ Pesquisadora EMBRAPA Pecuária Sudeste (patricia@cppse.embrapa.br).

5 Professor do Departamento de Informática/UFV (jivo@ufv.br).
} 
O cultivar Xaraés é indicado para solos de média fertilidade, bem drenados e de textura média (Valle et al., 2003). Essa forrageira é uma planta cespitosa que pode enraizar nos nós basais e apresenta altura média de 1,5 m. Em ensaios em canteiros, apresentou elevada produção de forragem, chegando a 21 t/ha de matéria seca com 30\% desse rendimento no período seco (Valle et al., 2001). É uma forrageira de estabelecimento rápido e com rebrotação superior à do cultivar Marandu. O florescimento é tardio e concentrado em maio/junho e a produtividade de sementes puras chega a $120 \mathrm{~kg} / \mathrm{ha} /$ ano (Valle et al; 2003).

Como a produtividade das gramíneas forrageiras está diretamente relacionada à sua capacidade de emitir folhas de meristemas remanescentes após a desfolhação (Nabinger, 1997), estudos básicos envolvendo morfologia, fisiologia e ecofisiologia do cultivar Xaráes certamente contribuirão para o estabelecimento de melhor estratégia de manejo, otimizando a produção e utilização dessa forrageira.

A programação morfogênica, cuja taxa é dependente da temperatura determina o funcionamento e o arranjo dos meristemas em termos de produção e expansão de novas células, que, por sua vez, definem a dinâmica de expansão dos órgãos (folha, entrenó, perfilho) e as exigências de carbono e nitrogênio (N) necessárias para essa expansão (Durant et al., 1991).

$\mathrm{O}$ aumento do teor de nitrogênio no solo por meio de fertilização é uma das formas de incrementar a produtividade nas pastagens, principalmente quando a forrageira responde à aplicação desse nutriente. Vários trabalhos relatam a importância da adubação nitrogenada na morfogênese e no perfilhamento de plantas forrageiras (Pearse \& Wilman, 1984; Alexandrino, 2000; Garcez Neto et al., 2001).

Considerando-se que para plantas de clima tropical o impacto da estratégia de manejo do pastejo sobre suas características morfogenéticas ainda é pouco conhecido (Carvalho et al., 2000), torna-se essencial que estudos sobre a dinâmica de produção das gramíneas forrageiras por meio de avaliações de características morfogênicas sejam conduzidos para gerar conhecimentos básicos para definição de práticas adequadas de manejo, principalmente para gramíneas recém-lançadas, como o cultivar Xaraés.

Este estudo foi realizado com o objetivo de se avaliar a influência da adubação nitrogenada e do regime de desfolhação sobre as características morfogênicas, estruturais e de produção de matéria seca da parte aérea e da raiz de plantas de Brachiaria brizantha cv. Xaraés.

\section{Material e Métodos}

O experimento foi conduzido em casa de vegetação no Departamento de Zootecnia da Universidade Federal de Viçosa, Minas Gerais. O município de Viçosa está localizado na região da Zona da Mata Mineira, numa altitude de $651 \mathrm{~m}$ acima do nível do mar, nas seguintes coordenadas geográficas: $20^{\circ} 45^{\prime} 40^{\prime \prime}$ de latitude sul e $42^{\circ} 51^{\prime} 40^{\prime \prime}$ de longitude oeste. O tipo climático é Cwa, segundo classificação de Koppen.

Os tratamentos consistiram da combinação de quatro doses de nitrogênio $\left(0,40,80\right.$ e $\left.120 \mathrm{mg} / \mathrm{dm}^{3}\right)$ e três regimes de desfolhação (duas, quatro e cinco folhas completamente expandidas antes do corte), avaliados em esquema fatorial $4 \times 3$, segundo um delineamento inteiramente casualizado, com quatro repetições, perfazendo um total de 48 unidades experimentais. Para determinação do número de folhas expandidas antes do corte, adotou-se o critério do número máximo de folhas vivas para a espécie, segundo Gomide (1997). Assim, para o capim-xaraés, utilizou-se como base o capim-marandu, uma vez que para a referida espécie o número máximo de folhas vivas expandidas ainda não foi determinado.

A análise inicial do solo apresentou o seguinte resultado: $\mathrm{pH}$ em água $=5,73 ; \mathrm{P}=4,4 \mathrm{mg} / \mathrm{dm}^{3} ; \mathrm{K}=$ $40 \mathrm{mg} / \mathrm{dm}^{3} ; \mathrm{Ca}^{2+}=2,5 \mathrm{cmol}_{\mathrm{C}} / \mathrm{dm}^{3} ; \mathrm{Mg}^{2+}=1,54 \mathrm{cmol}_{\mathrm{C}^{\prime}}$ $\mathrm{dm}^{3} ; \mathrm{H}+\mathrm{Al}=5,3 \mathrm{cmol}_{\mathrm{C}} / \mathrm{dm}^{3}$. Os vasos com capacidade de 5,8 dm ${ }^{3}$ e com orifícios para dreno do excesso de água receberam amostras de solo fertilizadas com $300 \mathrm{mg} / \mathrm{dm}^{3}$ de $\mathrm{P}_{2} \mathrm{O}_{5}$. O capim-xaraés foi semeado em bandejas contendo substrato agrícola comercial e, após 15 dias, foi transplantado em cinco plantas/vaso. O desbaste foi realizado 19 dias após o transplantio deixando-se três plantas/vaso. Trinta dias após o desbaste, as plantas receberam um corte de uniformização a $5 \mathrm{~cm}$ da superfície do solo no vaso.

Para avaliação das características morfogênicas, cada uma das plantas nos vasos recebeu um fio de cor diferenciada, para identificação dos perfilhos que foram utilizados para avaliação das características morfogênicas. As amostras de solo nos vasos foram mantidas próximo à sua capacidade de campo, com irrigação diária. Para todos os tratamentos, as doses de $\mathrm{N}$ e K (240 mg/dm ${ }^{3}$ ) foram parceladas em quatro apliações. A primeira aplicação foi feita três dias após o corte de uniformização, independentemente do tratamento. A partir daí, as aplicações se diferenciaram entre os tratamentos, de modo a permitir que as plantas recebessem a adubação nitrogenada de acordo 
com o seu próprio desenvolvimento, uma vez que o tratamento de regime de desfolhação era determinado pela expansão completa da folha (lígula exposta). Assim, as plantas que seriam colhidas ao exporem duas, quatro e cinco folhas completamente expandidas receberam, respectivamente, a segunda dose de adubação ao expandirem uma, três e quatro folhas. A terceira e quarta partes das doses foram aplicadas, respectivamente, uma e duas semanas após o corte (de acordo com o número de folhas expandias), realizado a $5 \mathrm{~cm}$ do solo. A partir do corte nas respectivas freqüências, as plantas foram avaliadas quanto às características morfogênicas e estruturais e à produção de matéria seca. Diariamente, foram registradas as temperaturas mínima e máxima no interior da casa de vegetação, para expressão dos resultados de filocrono em graus dia (GD), utilizando-se as equações proposta por Ometto (1981).

Os três perfilhos marcados inicialmente foram avaliados a cada dois dias, por meio do registro do dia de aparecimento do ápice foliar, do dia da exposição da lígula, comprimento final das folhas expandidas e em expansão, da senescência foliar (comprimento total da lâmina menos o comprimento da lâmina ainda verde) e do número de folhas vivas por perfilho. $\mathrm{O}$ número total de perfilhos por vaso foi quantificado ao final do período experimental. As características avaliadas foram: taxa de alongamento foliar (TAlF) - cm/dia e cm/GD; taxa de aparecimento foliar (TApF) - folhas/ dia e folhas/GD; filocrono (número de dias para o aparecimento de duas folhas consecutivas) - dias e GD; furação de vida da folha-dias e graus dias; Comprimento final da lâmina (CFL) - cm; número de folhas vivas por perfilho (NFV); número total de perfilhos (NTP) e taxa de senescência foliar (TSe) - cm/dia.

Após a morte da primeira folha completamente expandida em duas plantas de cada unidade experimental, cessaram-se as avaliações morfogênicas. As plantas foram colhidas e encaminhadas ao laboratório, para separação de seus componentes (lâmina, colmo + bainha e material morto). A área foliar das plantas de cada vaso foi mensurada antes de as folhas serem levadas à estufa juntamente com os outros componentes da planta, para determinação da produção total de MS, produção de lâmina, colmo e material morto. Avaliou-se também a relação lâmina:colmo. As raízes foram retiradas com lavagem em peneiras e levadas para secagem e determinação da produção de MS radicular.
Os dados referentes às características avaliadas foram submetidos à análise de regressão em função das doses de nitrogênio e freqüências de corte, selecionando-se as equações pelo coeficiente de determinação $\left(\mathrm{R}^{2}\right)$ e pela significância de $5 \%$ dos coeficientes, de acordo com o teste $T$. As equações de regressão foram ajustadas com base nas médias dos tratamentos, sendo o $\mathrm{R}^{2}$ SQReg/SQTrat.

\section{Resultados e Discussão}

A taxa de alongamento foliar(TAlF) foi influenciada $(\mathrm{P}<0,05)$ pela adubação nitrogenada e pelo regime de desfolhação, sem ocorrência de interação $(P>0,05)$ entre os fatores (Figura 1). Observou-se que o incremento na TAlF foi de até $37 \%$ para a mais elevada dose de $\mathrm{N}\left(120 \mathrm{mg} / \mathrm{dm}^{3}\right)$ em relação à ausência de adubação nitrogenada. Em alguns trabalhos avaliando os efeitos do $\mathrm{N}$ sobre a taxa de alongamento foliar, também foram obtidos resultados semelhantes (Gastal \& Nelson, 1994; Duru \& Ducrocq, 2000). Esse aumento na TAlF, promovido pela adubação nitrogenada, é atribuído por Volenec \& Nelson (1994) à maior produção de células. Em gramíneas, o alongamento foliar está restrito à uma zona na base da folha em expansão protegida pelo pseudocolmo (Skinner \& Nelson, 1995). A capacidade da planta em expandir suas folhas é dependente da taxa de alongamento do meristema intercalar (zonas de divisão celular). Essa zona de alongamento é um local ativo de grande demanda por nutrientes (Skinner \& Nelson, 1995). Segundo Gastal \& Nelson (1994), o maior acúmulo de $\mathrm{N}$ encontra-se na zona de divisão, explicando a resposta positiva do capim-xaraés à adubação nitrogenada.

Por outro lado, à medida que se elevou o número de folhas expandidas antes do corte (duas para cinco folhas), diminuiu-se a TAlF. Isso deveu-se ao fato de que plantas colhidas com menos folhas apresentaram maiores valores para essa variável, talvez como forma de recuperar mais rapidamente seu aparato fotossintético, tendo em vista que o vigor de rebrotação e, conseqüentemente, sua permanência no ecossistema, está diretamente relacionada à sua capacidade de emissão de folhas após a desfolhação. A TAlF é uma medida de grande importância na análise de fluxo de tecidos das plantas e correlaciona-se positivamente com o rendimento forrageiro (Horst et al., 1978). 
Na Figura 2, observa-se que a TApF respondeu linear e positivamente somente às doses de $\mathrm{N}(\mathrm{P}<0,05)$. Os valores variaram de 0,096 (sem adubação nitrogenada) para 0,121 folhas/dia (120 mg/dm³ $\mathrm{de} \mathrm{N}$ ), com aumento de $25 \%$ nessa variável quando comparado à ausência de aplicação de N. Essa amplitude de valores é superior àquela verificada por Cavalcante et al. (2002), em Brachairia decumbens sob pastejo, em que os valores variaram entre 0,079 e 0,107 folhas/dia.

O resultado do inverso da taxa de aparecimento foliar-denominado filocrono - indica o tempo (em dias ou em graus dia) necessário para o aparecimento de duas folhas consecutivas. Uma vez que o filocrono é um processo termo-dependente, a expressão dos resultados em tempo térmico (graus dia) é de extrema importância, visto que as plantas não respondem ao calendário humano. Neste ensaio, o filocrono do capim-xaraés apresentou resposta linear negativa para as doses de $\mathrm{N}(\mathrm{P}<0,05)$ tanto para os resultados expressos em dias quanto em graus dia. Os valores encontrados foram de 11,45 e 8,81 dias (Figura 3) e de 126,42 e 96,94 GD (Figura 4), sem adubação e com $120 \mathrm{mg} / \mathrm{dm}^{3}$ de $\mathrm{N}$, respectivamente.

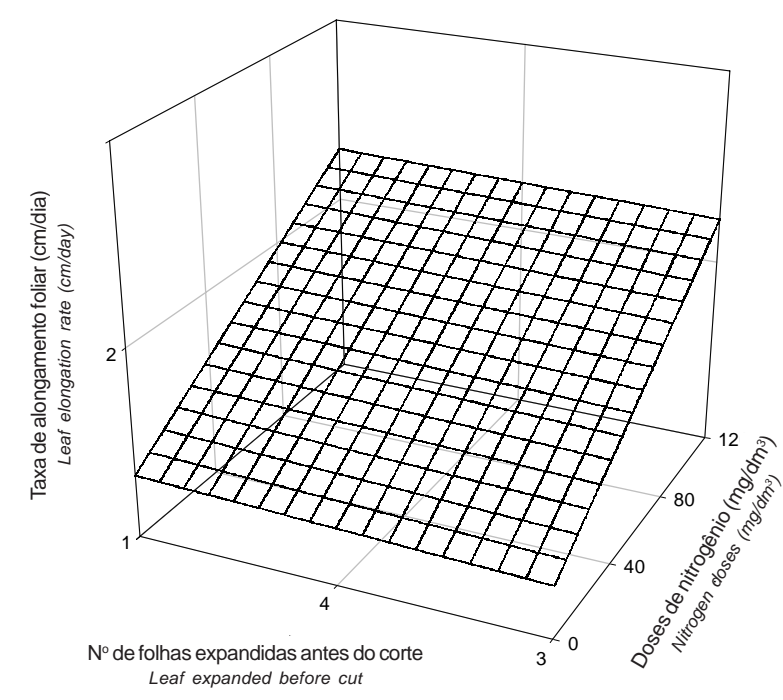

$\hat{\mathrm{Y}}=2,56+0,0061 * N-0,17 * \mathrm{D} \quad \mathrm{R}^{2}=92 \%$

* Significativo pelo teste $t(P<0,05)$

Figura 1 - Taxa de alongamento foliar (cm/dia) em plantas de capim-xaraés, em função das doses de nitrogênio $\left(\mathrm{mg} / \mathrm{dm}^{3}\right)$ e do regime de desfolhação.

Figure 1 - Leaf elongation rate (cm/day) of xaraésgrass submitted to nitrogen fertilization and defoliation.
O N exerceu um papel de extrema importância no desenvolvimento de plantas de capim-xaraés, pois favoreceu a recuperação de seu aparato fotossintético após a desfolhação, reduzindo o tempo para o aparecimento de duas folhas consecutivas. Isso evidencia a importância do N em uma série de processos fisiológicos (Nabinger, 2001), inclusive no aparecimento foliar.

Neste caso, a forma de expressão do filocrono não alterou o resultado, mas é recomendável que seja expresso pelo tempo térmico (graus dia), uma vez que diferentes localidades apresentam em determinado tempo uma soma calórica diferente e essa diferença poderá promover discrepância nos resultados.

A duração de vida da folha (DVF) sofreu influência linear negativa $(\mathrm{P}<0,05)$ somente da adubação nitrogenada $\left(\hat{\mathrm{Y}}=41,48-0,045 \mathrm{~N} ; \mathrm{R}^{2}=83 \%\right)$. Com base nos resultados, pode-se inferir que as plantas na ausência de $\mathrm{N}$ permaneceram mais tempo com suas folhas vivas em detrimento da expansão de novas folhas. Assim, os resultados de decréscimo na DVF com as doses de $\mathrm{N}$ são explicados pela maior renovação de tecidos em plantas adubadas com nitrogênio. A estimativa para DVF variou de 41,5 dias (496 GD) para as plantas sem adubação nitrogenada e 36,08 dias (487 GD) para as plantas supridas com $120 \mathrm{mg} / \mathrm{dm}^{3}$ de N. Mazzanti et al. (1994) ressaltaram que, em geral, ocorre diminuição na DVF em alta disponibilidade de N, em função da competição por luz, determinada pelo aumento da taxa de alongamento foliar e pelo maior tamanho final das folhas.

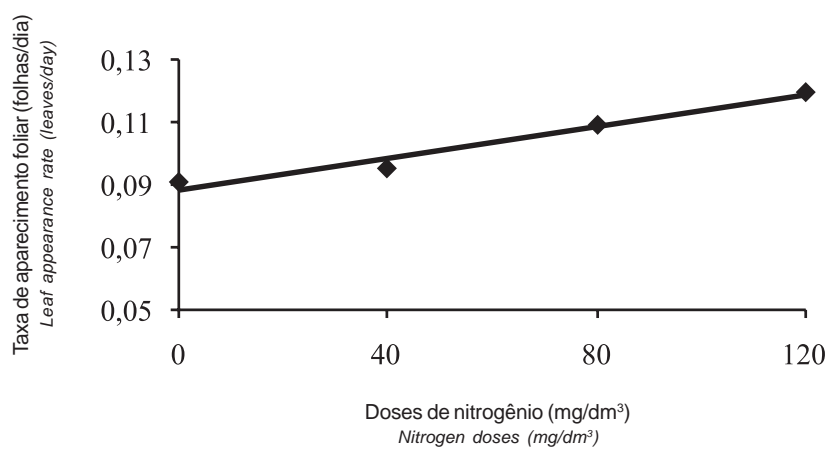

$\hat{Y}=11,45-0,022 * N \quad R^{2}=75 \%$

* Significativo pelo teste $t(P<0,05)$

Figura 2 - Taxa de aparecimento foliar (folha/dia) em plantas de capim-xaraés, em função das doses de nitrogênio.

Figure 2 - Leaf appearance rate (leaf/day) of xaraésgrass submitted to nitrogen fertilization and defoliation. 


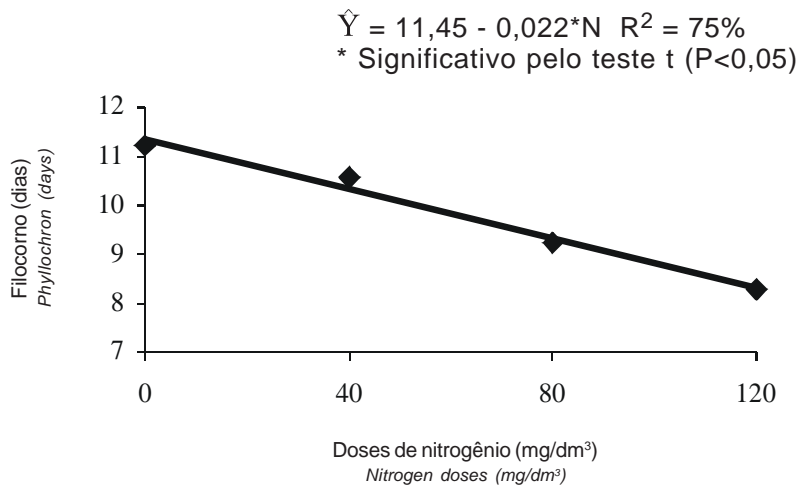

Figura 3 - Filocrono (dias) em plantas de capim-xaraés, em função das doses de nitrogênio.

Figure 3 - Phyllochron (days) of xaraésgrass submitted to nitrogen fertilization.

Segundo Gastal \& Nelson (1999), a DVF parece ser pouco afetada pela disponibilidade de N. O conhecimento dessa variável é fundamental no manejo da pastagem, pois indica o máximo potencial de rendimento da espécie, ou seja, a máxima quantidade de material vivo por área (Nabinger, 2001). Segundo esse autor, quando se aumenta a dose de $\mathrm{N}$ aplicada, sem o conseqüente ajuste da carga animal, no caso de lotação contínua ou de diminuição no intervalo de descanso em lotação intermitente, pode-se estar permitindo aumento exagerado da senescência, acúmulo de material morto e queda na taxa de crescimento da pastagem.

A DVF é melhor entendida quando analisada em conjunto com a taxa de senescência (TSe) e com o comprimento final da lâmina foliar (CFL). Assim, quando se observa a TSe evidencia-se que esta respondeu positivamente à adubação nitrogenada $(\mathrm{P}<0,05)$, e negativamente ao aumento do número de folhas expandidas antes do corte $(\mathrm{P}<0,05)$, sem haver interação $(\mathrm{P}>0,05)$ entre os fatores $(\hat{\mathrm{Y}}=0,66+0,0019 \mathrm{~N}$ $\left.-0,061 \mathrm{D} ; \mathrm{R}^{2}=68 \%\right)$. Isto provavelmente, ocorreu pelo fato de que plantas na ausência de aplicação de $\mathrm{N}$ permanecem com baixa TSe foliar, como estratégia para sobrevivência em virtude do decréscimo de seu metabolismo. A TSe (cm/dia) variou de $0,36 \mathrm{~cm} / \mathrm{dia}$ (plantas sem adubação e colhidas com cinco folhas) a $0,77 \mathrm{~cm} /$ dia (plantas que receberam $120 \mathrm{mg} / \mathrm{dm}^{3} \mathrm{de} \mathrm{N}$ e colhidas com duas folhas).

O número de folhas vivas (NFV) por perfilho elevou-se $(\mathrm{P}<0,05)$, à medida que se incrementou a adubação nitrogenada $(\mathrm{P}<0,01)$, e diminuiu $(\mathrm{P}<0,05)$

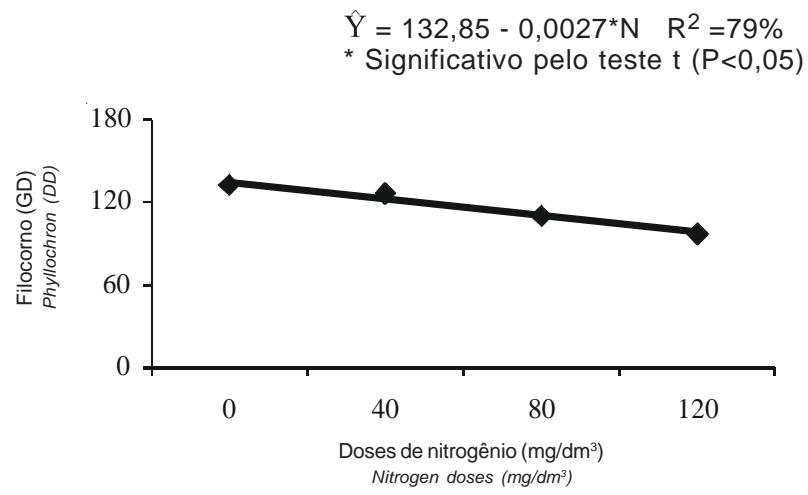

Figura 4 - Filocrono (GD) de plantas de capim-xaraés, em função das doses de nitrogênio.

Figure 4 - Phyllochron (DD) of xaraésgrass submitted to nitrogen fertilization.

com o aumento do número de folhas expandidas antes do corte, porém, não se observou interação $(\mathrm{P}>0,05)$ entre os fatores $(\hat{\mathrm{Y}}=4,43+0,0094 \mathrm{~N}-0,1216 \mathrm{D}$; $\mathrm{R}^{2}=84 \%$ ). Verificou-se que o NFV variou de 4,06 (plantas sem adubação nitrogenada e colhidas com cinco folhas) a 5,5 (plantas que receberam $120 \mathrm{mg} /$ $\mathrm{dm}^{3}$ de $\mathrm{N}$ e colhidas com duas folhas). Nos tratamentos com menores doses de $\mathrm{N}$, ocorreu maior DVF e menor NFV. O NFV por perfilho é resultante da DVF e, portanto, constitui uma característica genotípica bastante estável na ausência de deficiências nutricionais (Nabinger, 2001). Neste ensaio, observou-se NFV por perfilho de 4,73; 4,58 e 4,34 para os corte com duas, quatro e cinco folhas completamente expandidas.

O comprimento final da lâmina (CFL) respondeu $(\mathrm{P}<0,05)$ tanto à adubação nitrogenada como ao regime de desfolhação sem, contudo, ocorrer interação $(\mathrm{P}>0,05)$ entre os fatores $(\hat{\mathrm{Y}}=47,12+0,046 \mathrm{~N}-$ $\left.2,50 \mathrm{D} ; \mathrm{R}^{2}=88 \%\right)$. Portanto, para essa variável, houve aumento linear positivo à medida que se incrementou as doses de $\mathrm{N}$ e efeito linear negativo à medida que o o número de folhas expandidas antes do corte elevou. Embora tenha-se observado maior TSe em plantas com maior suprimento de $\mathrm{N}$, o NFV aumentou. Isso ocorreu pelo fato de se ter evidenciado maiores comprimentos de lâmina e, portanto, maior NFV nas plantas com maior suprimento de N. Além disso, observou-se maior TAlF, TApF e menor filocrono nessas plantas. Constatou-se, ainda, que plantas colhidas com duas folhas completamente expandidas apresentaram maior tamanho médio das folhas. O aumento no tamanho final da lâmina em função dos 
tratamentos em estudo pode evidenciar a ação do $\mathrm{N}$ como promotor do processo de divisão celular, estimulando a produção de novas células e possibilitando, conseqüentemente, aumento na taxa e alongamento foliar, que pode gerar mudanças no tamanho final da folha.

O CFL de capim-xaraés variou de 33,82 a 47,84 cm nas plantas sem adubação nitrogenada colhidas com cinco folhas e adubadas com $120 \mathrm{mg} / \mathrm{dm}^{3}$ de $\mathrm{N}$, cortadas com duas folhas, evidenciando que, em condições favoráveis de adubação, a divisão celular é beneficiada. Segundo Lemaire \& Agnusdei (1999), a DVF é o determinante do NFV, porém, neste experimento, isso não ocorreu. Entretanto, quando se considera que o número de folhas reflete o potencial fotossintético da planta, pode-se inferir que o $\mathrm{N}$ aumentando o NFV e o CFL, incrementa a capacidade de assimilação de carbono.

A área foliar (AF) do capim-xaraés aumentou $(\mathrm{P}<0,05)$ com a adubação nitrogenada (Figura 5), não sofrendo efeito $(\mathrm{P}>0,05)$ do regime de desfolhação. $\mathrm{O}$ incremento nessa variável foi de até $130 \%$ para a dose de $120 \mathrm{mg} / \mathrm{dm}^{3}$ de $\mathrm{N}$ em comparação à ausência de aplicação do nutriente.

A adubação nitrogenada promove aumento na taxa de alongamento foliar, havendo, conseqüentemente, efeito direto sobre a área foliar fotossintetizante. Além dessa influência, o $\mathrm{N}$ é fator controlador dos diferentes processos de crescimento e desenvolvimento das plantas e proporciona aumento de biomassa devido ao incremento na fixação de carbono (Nabinger, 2001). Assim, maior área para captação de energia pode promover maior acúmulo de biomassa.

De fato, a produção de matéria seca foliar (MSF) apresentou a mesma resposta que a AF em plantas de capim-xaraés, ou seja, houve resposta linear positiva $(\mathrm{P}<0,05)$ às doses de $\mathrm{N}$, sem haver efeito $(\mathrm{P}>0,05)$ da desfolhação ( $\left.\hat{Y}=31,24+0,11 N ; R^{2}=96 \%\right)$. A produção de MSF é uma característica importante para o crescimento das forrageiras, uma vez que a lâmina é o componente mais fotossinteticamente ativo na folha (Parson, 1993).

Assim como a produção de lâmina foliar, a MS do colmo também aumentou linear e positivamente $(\mathrm{P}<0,05)$ à medida que se elevaram as doses de $\mathrm{N}$ $\left(\hat{Y}=19,47+0,029 N, R^{2}=88 \%\right)$, sem efeito $(P>0,05)$ do regime de desfolhação. Os valores de produção de colmo foram de 18,95 e 22,62 g na ausência e com 120 $\mathrm{mg} / \mathrm{dm}^{3}$ de $\mathrm{N}$, respectivamente, significando aumento

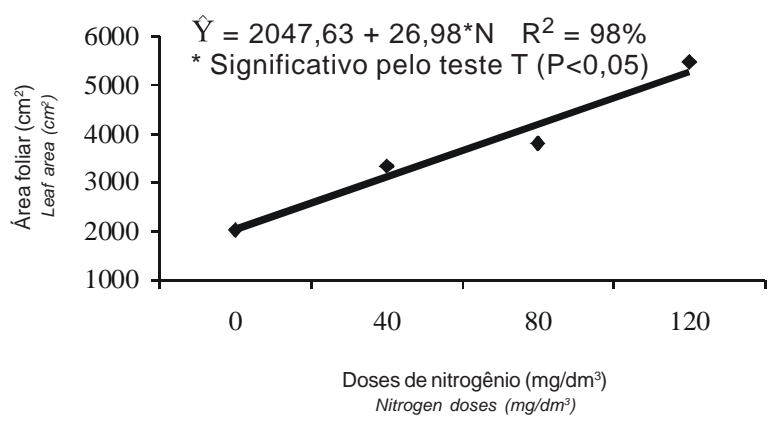

Figura 5 - Área foliar $\left(\mathrm{cm}^{2}\right)$ em plantas de capim-xaraés, em função das dose de nitrogênio.

Figure 5 - Leaf area $\left(\mathrm{cm}^{2}\right)$ of xaraésgrass submitted to nitrogen fertilization.

de até 19\%. As produções de MS de lâmina e colmo promovem efeito direto na relação lâmina:colmo, ou seja, quanto maior a produção de lâmina foliar, maior será essa relação, indicando melhor qualidade da planta forrageira, uma vez que a lâmina é o componente vegetal de maior digestibilidade. Neste experimento, a relação lâmina:colmo respondeu somente à adubação nitrogenada $(\mathrm{P}<0,05)$, apresentando efeito linear e positivo $(\hat{\mathrm{Y}}=1,62+0,0029 \mathrm{~N}$; $\mathrm{R}^{2}=86 \%$ ). Segundo Gomide (1997), a adubação promove aumento no rendimento forrageiro, em razão da maior eficiência fotossintética das folhas, do intenso perfilhamento e do alongamento do colmo, que, por sua vez, determina alterações indesejáveis na qualidade da forragem pela diminuição da relação lâmina:colmo. O alongamento de colmo do capimxaraés não alterou a qualidade da forragem, uma vez que a produção de lâmina foliar apresentou comportamento linear positivo à medida que se incrementou a adubação nitrogenada. Observou-se relação lâmina:colmo de 1,6 a 1,99 nas plantas na ausência de aplicação de $\mathrm{N}$ e adubadas com $120 \mathrm{mg} / \mathrm{dm}^{3}$ de $\mathrm{N}$, respectivamente.

Assim como a MSF e de colmo, a produção de MS da parte aérea respondeu $(\mathrm{P}<0,05)$ às doses de $\mathrm{N}$. Entretanto, para essa variável, houve também efeito $(\mathrm{P}<0,05)$ do regime de desfolhação, sem interação $(\mathrm{P}>0,05)$ entre os fatores. Desta forma, observa-se na Figura 6 aumento linear na produção de MS da parte aérea com o incremento da adubação nitrogenada e com o aumento do número de folhas expandidas antes do corte. Os valores variaram de $53 \mathrm{~g}$ (plantas 
sem adubação nitrogenada e colhidas com duas folhas) a $77 \mathrm{~g}$ (plantas na dose de $120 \mathrm{mg} / \mathrm{dm}^{3}$ de $\mathrm{N}$ e colhidas com 5 folhas).

Diversos estudos comprovam a considerável significância do $\mathrm{N}$ sobre a produção de plantas forrageiras e sua influência sobre as características morfogênicas e estruturais dentro da comunidade vegetal (Simon \& Lemaire, 1987; Mazzanti et al., 1994; Pieterse et al., 1997). Em capim-xaraés, o incremento para a MS da parte aérea foi bem inferior ao observado por Alexandrino (2000). Independentemente da magnitude dos efeitos do $\mathrm{N}$ sobre a produção de MS, a influência desse nutriente pode ser atribuída ao aumento na TApF (Thomas, 1983) que reflete na TAlF, contribuindo para o crescimento do vegetal e resultando em aumento na área foliar (Paciullo et al., 1998). Quanto ao regime de desfolhação (Figura 6), plantas colhidas com duas folhas expandidas apresentaram maior produção de MST. Isso provavelmente se deu pelo fato de que plantas colhidas com maior número de folhas expandidas puderam armazenar mais reservas antes do corte, permitindo rebrotação mais vigorosa.

A MS do sistema radicular do capim-xaraés, ao contrário de todas as outras variáveis analisadas, não respondeu $(\mathrm{P}>0,05)$ à adubação nitrogenada. Observou-se relação linear positiva $(\mathrm{P}<0,05)$ entre a MS radicular e o regime de desfolhação ( $\hat{Y}=188,7+$ $98,72 \mathrm{D} ; \mathrm{R}^{2}=99 \%$ ), ou seja, à medida que se aumentou o número de folhas expandidas antes do corte, houve incremento na MS da raiz. Isso sugere que plantas colhidas mais freqüentemente têm seu sistema radicular comprometido, uma vez que o estresse da desfolha precoce e muito intensa $(5 \mathrm{~cm})$ promove mobilização de reservas das raízes para recuperação da área foliar.

Segundo Thornton \& Millard (1997), repetidas desfolhações em gramíneas causam reduções no crescimento radicular quando essas plantas são comparadas àquelas não desfolhadas. No caso do capimxaraés, observaram-se aumentos de 135 a 191 g de MS/vaso para, respectivamente, desfolhação com duas e cinco folhas completamente expandidas. A desfolhação afeta também a capacidade de absorção de N pelo sistema radicular. Neste sentido, Clemente (1978) registrou para Lolium perenne queda na absorção de nitrato em plantas que sofreram repetidas desfolhações. Isso explica porque plantas de capimxaraés cortadas com maior freqüência (duas folhas expandidas) apresentaram menor acúmulo de biomassa aérea.

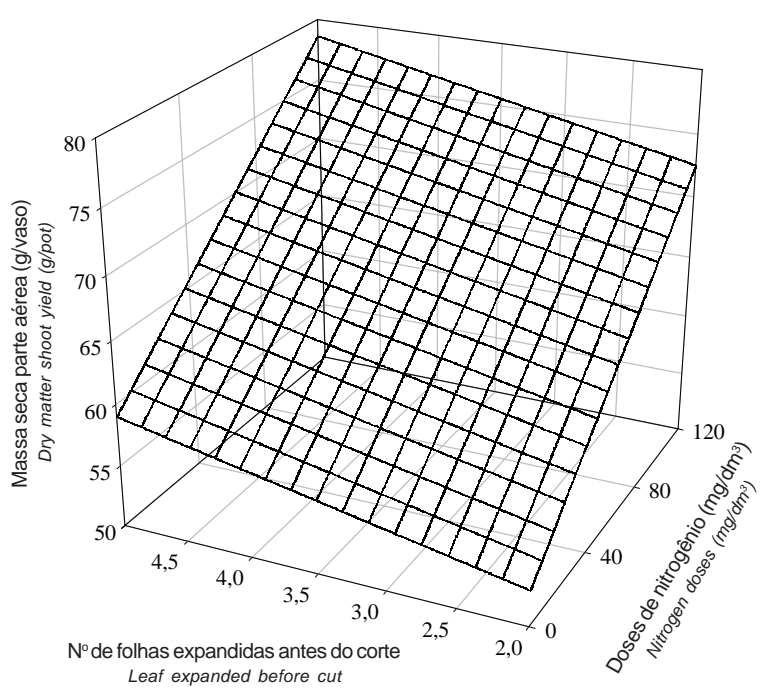

$\hat{Y}=48,92+0,16^{*} N+1,98^{*} D \quad R^{2}=90 \%$

* Significativo pelo teste $t(P<0,05)$

Figura 6 - Matéria seca da parte aérea em plantas de capim-xaraés, em função das doses de nitrogênio e do regime de desfolhação.

Figure 6 - Dry matter shoot yield of xaraésgrass submitted to nitrogen fertilization and defoliation.

\section{Conclusões}

A adubação nitrogenada exerce efeito positivo nas taxas de alongamento e aparecimento foliar, no número de perfilhos, de folhas vivas e no comprimento final da lâmina em plantas de capim-xaraés.

O processo de senescência foliar nesta forrageira é acelerado com o aumento das doses de nitrogênio, reduzindo a duração média de vida das folhas.

O aumento do número de folhas expandidas antes do corte propicia incremento na taxa de alongamento foliar e na proporção de matéria seca das raízes e reduz a taxa de senescência, o comprimento final da lâmina e o número de folhas vivas por perfilho em plantas de capim-xaraés.

A adubação nitrogenada e o aumento do número de folhas expandidas antes do corte elevam a produção de matéria seca da parte aérea de capim-xaraés.

\section{Literatura Citada}

ALEXANDRINO, E. Crescimento e características químicas e morfogênicas da Brachiaria brizantha cv. Marandu submetida a cortes e diferentes doses de nitrogênio. Viçosa, MG: Universidade Federal de Viçosa, 2000. 70p. Dissertação (Mestrado em Zootecnia) - Universidade Federal de Viçosa, 2000. 
CARVALHO, C.A.B.; Da SILVA, S.C.; SBRISSIA, A.F. et al. Demografia de perfilhamento e taxas de acúmulo de matéria seca em capim “tifton 85" sob pastejo. Scientia Agrícola v.57, n.4, p.591-600. 2000.

CAVALCANTE, M.A.B.; GOMIDE, J.A.; PEREIRA, O.G. et al. Características morfogênicas e estruturais do relvado de Brachiaria brizantha cv. Basilisk sob pastejo, em diferentes alturas. In: REUNIÃO ANUAL DA SOCIEDADE BRASILEIRA DE ZOOTECNIA, 38., 2002, Recife. Anais... Recife: Sociedade Brasileira de Zootecnia. 2002. p.101-103.

CLEMENT, C.R. The uptake of nitrate by Lolium perenne from flowing nutrient solution. II. Effect of light, defoliation, and relationship to $\mathrm{CO}_{2}$ flux. Journal of Experimental Botany, v.29, p.1173-1183, 1978.

DURANT, J.L.;VARLET-GRANCHER,C.; LEMAIRE, G. et al. Carbon partioning in forage. Acta biotheoretcia, v.30, p.213-224, 1991.

DURU, M.; DUCROCQ, H. Growth and senescence of the successive leaves on a Cocksfoot tiller. Effect of nitrogen and cutting regime. Annals of Botany, v.85, p.645-653, 2000a.

WOODWARD, S.J.R. Quantifying different causes of leaf and tiller death in grazed perennial ryegrass swards. New Zealand Journal of Agricultural Research, v.41, p.149-159. 1998

GARCEZ NETO, A.F.; NASCIMENTO JR., D.; REGAZZI, A.J. et al. Avaliação de características morfogênicas de Panicum maximum cv. Mombaça em resposta à adubação nitrogenada e alturas de corte. In: REUNIÃO ANUAL DA SOCIEDADE BRASILEIRA DE ZOOTECNIA, 38., 2002. Recife. Anais... Recife: Sociedade Brasileira de Zootecnia, 2002. p.104-106.

GASTAL, F.; NELSON, C.J. Nitrogen use whitin the growing leaf blade of tall fescue. Plant Physiology, v.105, p.191197, 1994.

GOMIDE, C.A. Morfogênese e análise de crescimento de cultivares de Panicum maximum (Jacq.). Viçosa, MG: Universidade Federal de Viçosa, 1997. 53p. Dissertação (Mestrado em Zootecnia)- Universidade Federal de Viçosa, 1997

HORST, G.L.; NELSON, C.J.; ASAY, K.H. Relationship of leaf elongation to forage yield of tall fescue genotypes. Crop Science, v.18, n.5, p.715-719, 1978.

LEMAIRE, G.; AGNUSDEI, M. Leaf tissue turn-over and efficiency of herbage utilization. In: GRASSLAND ECOPHYSIOLOGY AND GRAZING ECOLOGY, 1999. Curitiba, Brazil. Proceedings... Curitiba: 1999. p.165-186

MAZZANTI, A.; LEMAIRE, G.; GASTAL, F. The effect of nitrogen fertilization upon the herbage production of tall fescue swards continuously grazed with sheep. 1. Herbage growth dynamics. Grass and Forage Science, v.49, p.111-120, 1994.

NABINGER, C. Eficiência de uso de pastagens: disponibilidade e perdas de forragem. In: SIMPÓSIO SOBRE MANEJO DA PASTAGEM, 14., 1997, Piracicaba. Anais... Piracicaba: Escola Superior de Agricultura "Luiz de Queiroz”, 1997. p.231-251.
NABINGER, C. Manejo da desfolha In: SIMPÓSIO SOBRE MANEJO DA PASTAGEM, 14., 2001, Piracicaba. Anais... Piracicaba: Escola Superior de Agricultura "Luiz de Queiroz”. 2001. p.192-210.

OMETTO, J.C. Bioclimatologia vegetal. São Paulo: Ceres, 1981. 440p.

PACIULLO, D.S.C.; GOMIDE, J.A.; RIBEIRO, K.G. Adubação nitrogenada de capim-elefante cv. Mott 1. Rendimento forrageiro e características morfofisiológicas ao atingir 80 e $120 \mathrm{~cm}$ de altura. Revista Brasileira de Zootecnia, v. 27, n.6, p.1069-1075, 1998.

PARSONS, A.J.; LEAFE, E.L.; COLLET, B. et al. The physiology of grass production under grazing. 1. Characteristics of leaf and canopy photesyntesis of continuously grazed swards. Journal of Applied Ecology, v.20, p.117-136. 1983.

PEARSE, P.J.; WILMAN, D. Effects of applied nitrogen on grass leaf initiation, development and death in field swards. Journal Agriculture Science, v.103, n.2, p.405-413, 1984.

PIETERSE, P.A.; RETHMAN, N.F.G.; VAN BOSCH, J. Production, water use efficiency and quality of four cultivars of Panicum maximum at different levels of nitrogen fertilization. Tropical Grasslands, v.31, p.117-123. 1997.

SKINNER, R.H.; NELSON, C.J. Elongation of the grass leaf and its relationship to the phyllochron. Crop Science, v.35, n.1, p.4-10, 1995.

SIMON, J.C.; LEMAIRE, G. Tillering and leaf area index in grasses in the vegetative phase. Grass and Forage Science, v.42, p.373-380, 1987.

THOMAS, H. Analysis of the nitrogen response of leaf extension in Lolium temulentum seedlings. Annals of Botany, v.51, p.363-371, 1983.

THORNTON, B.; MILLARD, P. Increased defoliation frequency depletes remobilization of nitrogen for leaf growth in grasses. Annals of Botany, v.80, p.89-95, 1997.

VALLE, C.B.; EUCLIDES, V.P.B., MACEDO, M.C.M. et al. Selecting new Brachiaria for Brazilian pastures. In: INTERNATIONAL GRASSALAND CONGRESS, 19., São Pedro. Proceedings... Piracicaba: Escola superior de Agricultura “Luiz de Queiroz”, 2001. p.13-14.

VALLE, C.B.; JANK, L.; RESENDE, R.M.S. et al. Lançamentos de cultivares forrageiras: o processo e seus resultados - cvs. Massai, Pojuca, Campo Grande, Xaraés. In: NÚCLEO DE ESTUDOS EM FORRAGICULTURA, 4., 2003, Lavras. Proceedings... Lavras: Universidade Federal de Lavras, 2003. p.179-225.

VOLENEC, J.J.; NELSON, C.J. Carbohydrate metabolism in leaf meristems of tall fescue. II. Relationship to leaf elongation rates modified by nitrogen fertilization. Plant Physiology, v.74, p.595-600, 1984. 